\title{
TECHNICO-ECONOMIC STUDY OF A PHOTOVOLTAIC PUMPING SYSTEM USING A VARIABLE-FREQUENCY DRIVE CONVERTER.
}

\author{
L. Elmahni ${ }^{1}$, K. Assalaou ${ }^{1}$, E. aitiaz ${ }^{1}$, B. Benachir ${ }^{2}$, L. Bouhouch ${ }^{3}$ \\ ${ }^{1}$ Renewable Materials and Energies Laboratory (RMEL), Faculty of Sciences, Ibn Zohr University, Agadir-Morocco. \\ ${ }^{2}$ LASIME, ENSA, Ibn Zohr University, Agadir, Morocco. \\ ${ }^{3}$ SERA, Higher School of Technology of Agadir (HSTA), Ibn Zohr University, Agadir, Morocco
}

\begin{abstract}
This paper presents a technical-economic study of a photovoltaic pumping system using an inverter with a Variable Frequency Drive (VFD) to improve system efficiency. We propose a comparative study between two pumping station projects located in places very close to each other, in order to consider that they are exposed to the same meteorological data. One of the projects has the maximum power tracking technique (MPPT), while the other project does not have this technique. The study will compare the various experimental surveys carried out in the field with modeling results using Matlab Simulink.
\end{abstract}

\section{Introduction}

Morocco has launched several energy efficiency programs aimed at optimizing the energy performance of farms, by developing alternative energies, in particular solar pumping [1].

For several years, numerous researcheswork on solar pumping systems (SPS) have attracted the interest of researchers. Indeed, some authors [2] deal with the modeling and simulation in the MATLAB environment, of a SPS composed of a photovoltaic generator (PVG), converters, an asynchronous machine and a centrifugal pump. Other authors [3] present a comparative study of the performance characteristics of a PV system connected directly to a permanent magnet direct current motor, driving a centrifugal pump and a pumping system using a PPM tracking algorithm. Other works [4-6] present promising SPPV optimization techniques but remain to be validated in practice. In this sense, and based on experimental measurements carried out in the field, we propose a comparative study between the real performances of two solar pumping sites located, one from the other, approximately within a radius of $1 \mathrm{~km}$. The first project uses a low-cost frequency converter, which has undergone some modifications described below, in order to adapt to PV panels. This system is devoid of the principle of MPPT. The second project is relatively expensive compared to the first, but it has the advantage of being equipped with the MPPT principle. After this introduction, this paper is organized as follows: it first presents a description of the projects studied in section 1. Section 2 gives a brief economic study. Then section 3 presents the modeling under MATLAB / Simulink of the SPS as well as the measurement bench used. Section 4 is devoted to the analysis of the results and their discussion. Finally, a conclusion and perspectives complete this paper.

\section{Description of Projects}

Our study concerns two PV pumping projects located in the Agadir region, whose GPS coordinates are $\left(30.615149^{\circ},-9.351730^{\circ}\right)$ for "Site 1" and (30.606689 $\circ,-9.348471^{\circ}$ ) for the second "Site 2 ". The two projects are characterized by a total manometric head $\mathrm{TMH}=60 \mathrm{~m}$, a water flow $\mathrm{Q}=60 \mathrm{~m}^{3} /$ day. Because the 2 sites are close, we assume that their meteorological data is identical. The configurations adopted for the SPSs used in these projects are summarized in Table 1. Project 1 uses a frequency converter of the Mitsubishi FR-E740 type allowing to vary the speed of rotation of the pump by modifying

Table 1:Components of PV pumping stations

\begin{tabular}{|l|l|}
\hline \multicolumn{2}{|c|}{ Project 1 } \\
\hline \multicolumn{1}{|c|}{ Designation } & \multicolumn{1}{c|}{ Reference } \\
\hline 16 PV Modules & REC250PE- BLK \\
\hline Inverter (VFD) & Mitsubishi FR-E740-5.5K \\
\hline Pump & SP 11-15 - 98699316 \\
\hline \multicolumn{2}{|c|}{ Project 2 } \\
\hline \multicolumn{1}{|c|}{ Resignation } & \multicolumn{1}{|c|}{ Refence } \\
\hline 16 PV Modules & LC250-P60 \\
\hline Controller & LORENTZ PS 4000 \\
\hline Pump & EC-DRIVE-4000C+ PE SJ8-15-D \\
\hline
\end{tabular}

the voltage and the frequency of a three-phase voltage 400 V. Its standard synoptic diagram is given in Figure $1-a$. 


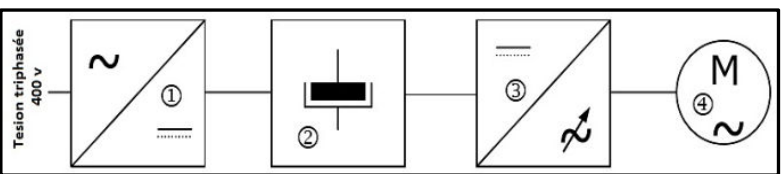

Fig. 1-a:Block diagram of a conventional frequency converter (not modified).

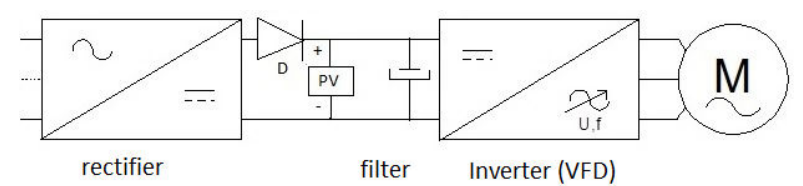

Fig. 1-b: Block diagram of a rectified frequency converter.

The diagram of Figure 1 has been modified according to Figure 1-b, in order to directly connect the DC voltage delivered by the PV panels to block 3 . In this diagram, $\mathrm{D}$ is a non-return diode. Table 2 illustrates the different blocks constituting the frequency converter shown schematically in Figure 1.

Table 2:Description of the blocks of a frequency converter

\begin{tabular}{|c|l|}
\hline Bloc & \multicolumn{1}{|c|}{ Function } \\
\hline $\mathbf{1}$ & Rectifier \\
\hline $\mathbf{2}$ & $\begin{array}{l}\text { Attenuates or eliminates the phenomena of } \\
\text { ripple voltage at the output of the rectifier. }\end{array}$ \\
\hline $\mathbf{3}$ & $\begin{array}{l}\text { Variable frequency DC-AC converter plus } \\
\text { maintaining the voltage to frequency }(U / f) \text { ratio } \\
\text { constant, thus avoiding increased induction in } \\
\text { the motor. }\end{array}$ \\
\hline $\mathbf{4}$ & Motor pump group \\
\hline
\end{tabular}

Project 1 is a pumping system that does not exploit the principle of MPPT research, it is commonly referred to as "Direct coupling". Project 2 includes an original German Lorentz PS 4000 controller, specially designed for solar pumping over the sun. It is equipped with MPPT technology to optimize the energy consumption of PV panels by the centrifugal pump.

\section{Economic study}

Economic analysis consists of considering all the costs of the components of our SPS over a period of time reduced to a present value. This makes it possible to compare the costs on a common basis with other options and thus find the most economical choice. This cost analysis should include the cost of financing the capital as well as the present value of the operating, maintenance and replacement costs over the expected life of the pumping system. This analysis is called the LCC (Life Cycle Cost) calculation [7, 8].

Equation (1) gives the formulation of the life cycle cost $(L C C)$ according to the acquisition price of the equipment $C_{0}$, the installation $\operatorname{cost} C_{\text {inst }}$, the cumulative cost of the maintenance $C_{c-\text { maint }}$ and the cumulative cost of $C_{c-\text { repl replacement }}$ [9].

$$
L L C=C_{0}+C_{\text {inst }}+C_{c-0}+C_{c-\text { ] }}
$$

$C_{c-\text { maint }}$ et $C_{c-\text { replare }}$ recurring and require updating throughout the system lifecycle. The cumulative cost $C_{c-r e p l}$ is expressed by equation (2) [9]:

$C_{c-\text { 回 }}=f_{a} C_{0}$

Where $\boldsymbol{f}_{\boldsymbol{a}}$ is the discount factor for the cost $C_{0}$ after n year later, such that [9]:

$$
f_{a}=\left(\frac{1+\tau}{1+d}\right)^{n}=x^{n} \quad \text { Avec } \quad x=\frac{1+\tau}{1+d}
$$

Where $\tau(=0.03)$ and $d(=0.05)$ correspond respectively to the inflation rate and the discount rate per year. The cumulative maintenance cost $C_{c-m a i n t}$ is formulated by equation (4) [9]

$$
C_{c-0}=C_{\text {maint }} x \frac{1-x^{n}}{1-x}
$$

The updated cost of a cubic meter of water $\boldsymbol{C}_{\boldsymbol{a m} 3}$ for the year ' $\mathrm{n}$ ' considered is given by equation (5) below [8]:

$$
C_{a m 3}=\frac{L C C}{365 n Q}
$$

\section{Modeling, Material and Method}

\subsection{Modeling}

Our SPP under test operates all day, thus allowing water storage rather than electricity. Our previous work [10] was devoted to the modeling of the main components of the system under Matlab / Simulink. However, it is essential to note that the continuation of the MPPT is carried out using the method "Perturb \& Observe" [11]. The diagram thus obtained under Simulink [12] is visible in Figure 2.

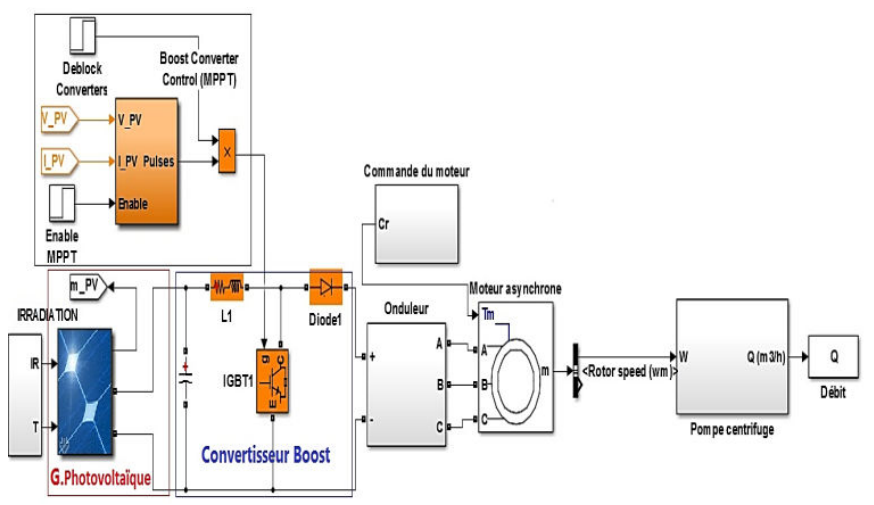

Fig. 2:Complete diagram of the SPS modeled under Simulink [10]
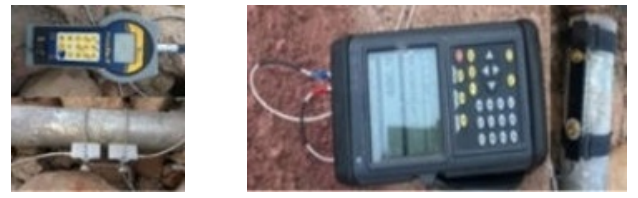

Fig. 3:Portable ultrasonic transit time flowmeter with its sensors: (left) PrimeFlo-T and (right) TransPort ${ }^{\circledR} P T 878$ 


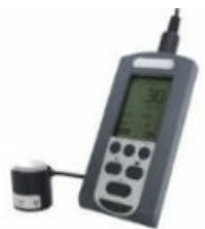

Fig. 4:KIMO SL200 Solarimeter

\subsection{Materials and measurement method}

During our investigations, we used measuring devices used to estimate solar irradiation and pumped water flow. This pumped water flow $\mathrm{Q}\left(\mathrm{m}^{3} / \mathrm{h}\right)$ is achieved for project 1 using the PrimeFlo-T flowmeter (Figure 3-left), and using the TransPort ${ }^{\circledR}$ PT 878 for project 2 (Figure 3-right). These portable devices incorporate DSPs allowing the measurement of water flows by exploiting a principle based on an ultrasonic technique. These flowmeters allow continuous flow monitoring throughout the day (48 hrs for PrimeFlo-T and $11 \mathrm{hrs}$ for TransPort ${ }^{\circledR}$ PT87), as well as the transfer of records to a computer. Regarding the measurement of the instantaneous irradiation Gd, it is carried out using the SL200 solarimeter from KIMO (Figure 4) [13]. The latter is a portable control and investigation tool providing irradiance values while memorizing them in $\mathrm{W} / \mathrm{m}^{2}$. Its rechargeable battery has an autonomy of 48 hours. This device comes with software to transfer data to a computer.

\section{Results and discussion}

\subsection{Technical analysis}

The SL200 solarimeter allowed us to record the irradiation for the two days considered (24/4/2016 and 13/11/2016) (Figure 5). These same values are injected into the "Irradiation" block visible on the Simulink diagram in Figure 2.

Table 3 gives some real indicators relating to the projects under study. The simulation results and the experimental records obtained are compared in Figures 6-a and 6-b for the two projects $1 \& 2$ without and with MPPT during the days of April 24 and November 13, 2016. These results show that the performances of project 2 with the MPPT principle are significantly better than those of project 1 .

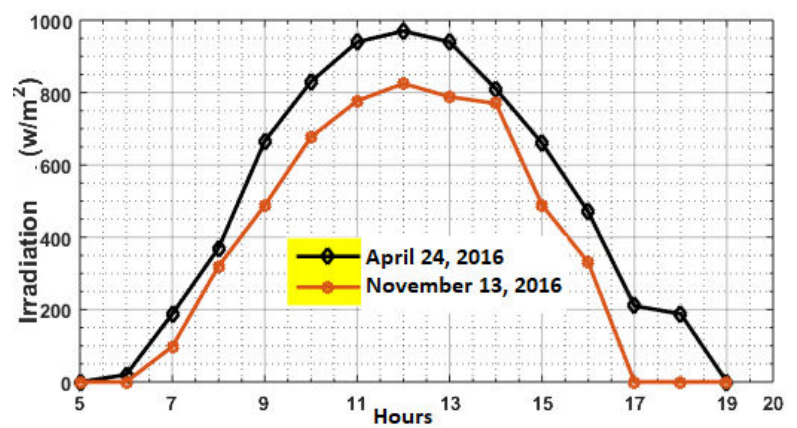

Fig.5: The Gd irradiations recorded on $04 / 24$ and 11/13/2016 on "Site 1
Table 3:Performance of projects 1 and 2

\begin{tabular}{|c|l|c|c|}
\hline \multicolumn{2}{|c|}{ Month } & $\begin{array}{c}\text { Monthly } \\
\text { average flow } \\
\left(\mathbf{m}^{3} / \mathbf{j}\right)\end{array}$ & $\begin{array}{c}\text { Flow of the day } \\
\text { considered }\left(\mathbf{m}^{3} / \mathbf{j}\right)\end{array}$ \\
\hline \multirow{3}{*}{ April } & Project 1 & 54 & 51 \\
\cline { 2 - 4 } & Project 2 & 73 & 74.3 \\
\cline { 2 - 4 } & Gain in $\mathrm{m}^{3}$ & $\mathbf{1 9}$ & $\mathbf{2 3 . 3}$ \\
\hline \multirow{3}{*}{ November } & Project 1 & 46 & 41 \\
\cline { 2 - 4 } & Project 2 & 59 & 59.6 \\
\cline { 2 - 4 } & Gain in $\mathrm{m}^{3}$ & $\mathbf{1 3}$ & $\mathbf{1 8 . 5}$ \\
\hline
\end{tabular}
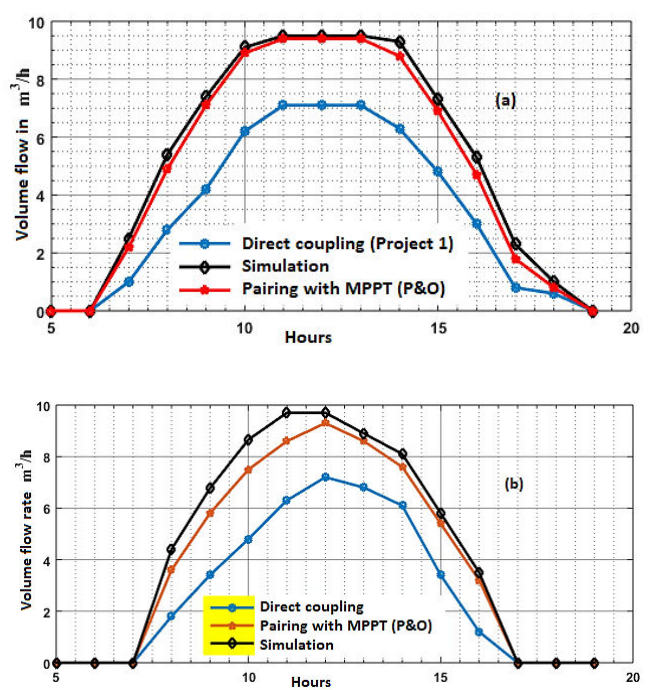

Fig. 6:Volume flow rates obtained for 2 projects $1 \& 2$ during: (a) April 24, 2016 and (b) November 13, 2016 Compared to simulations with MPPT

Figures 7-a and 7-b show the evolution of volume flow rates as a function of solar irradiation during 04/24/2016 and 11/13/2016, both measured and simulated. These curves show that during the month of April the pump starts delivering water from $200 \mathrm{~W} /$ $\mathrm{m}^{2}$. While during the month of November this threshold is $300 \mathrm{~W} / \mathrm{m}^{2}$.
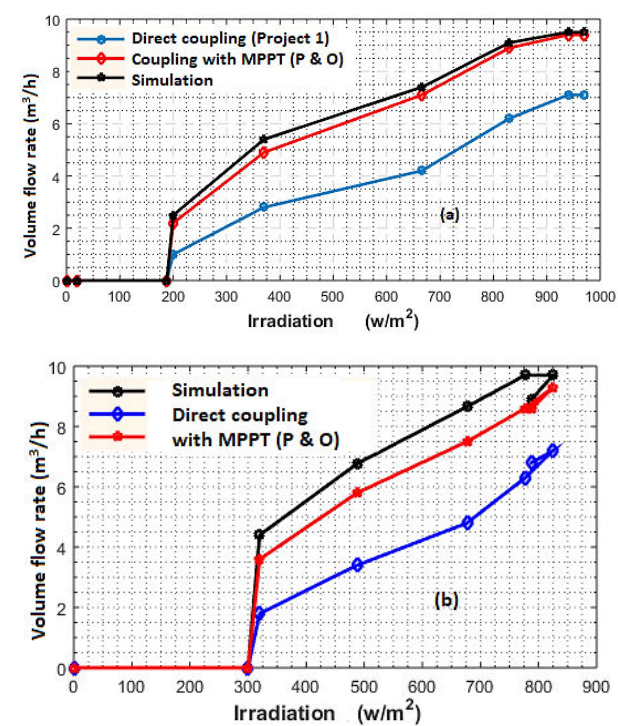

Fig.7: Evolution of volume flow rates as a function of solar irradiation during:

(a) $04 / 24 / 2016$ and (b) $11 / 13 / 2016$ compared to simulations with MPPT 
Figure 8 shows the volume flow yields (Qprojet / Qth) of the two projects under study on the days considered. These results show that the efficiency is low for low irradiations and increases towards $100 \%$ for high irradiations. These curves also show that the performances during the month of April are clearly superior to those of the month of November. These same results show that the performance of project 2 is significantly better than that of project 1 .

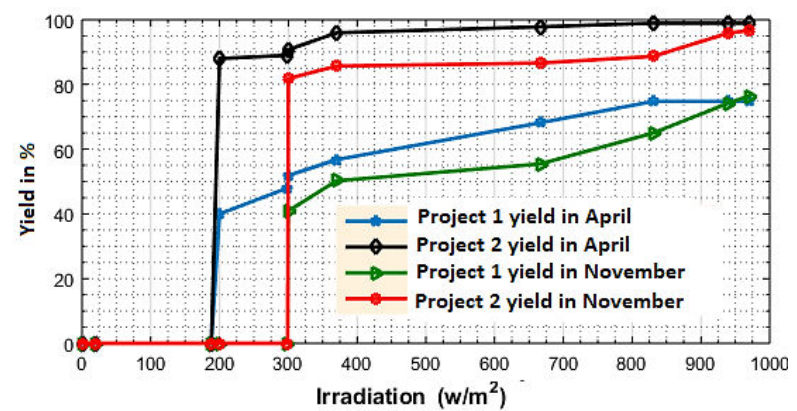

Fig.8:Yield in terms of volume flow of the projects under study on the days considered

\subsection{Economic analysis}

The adopted economic analysis is based on the determination of the updated global cost of the cubic meter $\left(\mathrm{m}^{3}\right)$ of water according to the daily flow rate, the total manometric head (TMH) and the sunshine of the installation site. In fact, to assess the updated global cost of the $\mathrm{m}^{3}$ of water pumped, it is necessary to have certain data, namely: the service life of each component, the cost or initial investment, the relative annual maintenance costs to the PV system, the costs of replacing the various subsystems. The profits made over the entire active life of the system represent other important parameters to consider in our calculations [14]. Equations (1), (2), (4) and (5) in section 2 are used to calculate the various costs: $L L C, C_{c \text {-repp }}, C_{c \text {-maint }}$ and $C_{a m 3}$. Figure 9 gives the economic summary on the comparison of the costs of $\mathrm{m}^{3}$ of water pumped by the two systems S1 and S2 according to the number of years of operation. These curves show that even if the investment of the S2 system is relatively greater than that of $\mathrm{S} 1$, the price of $\mathrm{m}^{3}$ of the $\mathrm{S} 2$ system is relatively lower than that of S1 from the start of the investment, and decreases rapidly over the years, to match an estimated price of 0.4 MAD after 25 years of service. The S1 system starts with a price of 7.10 MAD and decreases to $0.44 \mathrm{MAD}$ after 25 years.

Although pumping water by system without MPPT is interesting at first, given its low investment, the SPS with MPPT is more profitable after less than two years of use.

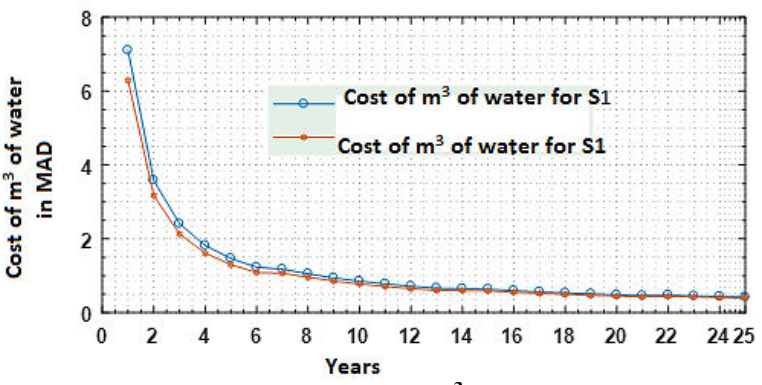

Fig. 9:Comparison of the costs of $\mathrm{m}^{3}$ of water pumped by the two systems $S 1$ and $S 2$ according to the number of years of operation

\section{Conclusion}

Les travaux de recherche présentés dans ce papier nous ont permis de comparer deux systèmes de pompage solaire : avec ou sans MPPT. Les différents relevés expérimentaux effectués sur le terrain avec les résultats de modélisation sous Matlab/Simulink, nous ont révélé que le projet doté de la technique MPPT apporte des améliorations du rendement du système de pompage PV. En parallèle à l'étude technique, une analyse économique est menée afin de choisir la meilleure solution énergétique à adopter en termes de coût. L'analyse adoptée dans notre cas d'étude a prouvé qu'à long terme, le système avec la MPPT est aussi plus rentable que le système dépourvu de cette stratégie.

\section{References}

1. Med Ener, AgenceMéditerranéenne des AgencesNationales de Maîtrise de l'Energie, "Indicateursd'efficacitéénergétique pour les pays méditerranéens", http://medener-

indicateurs.net/fr/documents-fourth-reunion.html, Consultedat 06/04/2018.

2. M. Arrouf, S. Ghabrour, "Modelling and simulation of a pumping system fed by photovoltaic generator within the Matlab/Simulink programming environment", Desalination, 209, 13 SPEC. ISS., pp. 23-30, (2007).

3. M. A. Elgendy, B. Zahawi, S. Member, D. J. Atkinson, "Comparison of Directly Connected and Constant Voltage Controlled Photovoltaic Pumping Systems", IEEE Trans. Sustain. ENERGY, 1, 3, pp. 184-192, (2010).

4. A. Oi, "Design and simulation of photovoltaic water pumping system", PHd thesis, Faculty of California Polytechnic State University, San Luis Obispo, (2005).

5. A. Hamidat, B. Benyoucef, "Mathematic models of photovoltaic motor-pump systems", Renew. Energy, 33, 5, pp. 933-942, (2008).

6. D. H. Muhsen, T. Khatib, F. Nagi, "A review of photovoltaic water pumping system designing methods, control strategies and field performance", Renew. Sustain. Energy Rev, 68, pp. 70-86, (2017) 
7. D. Abbes, "Contribution au dimensionnement et à l'optimisation des systèmeshybrideséoliensphotovoltaïques avec batteries pour l'habitatrésidentielautonome", PHd Thesis, Université de Poitiers, (2012).

8. D. Abbes, A. Martinez, G. Champenois, J. P. Gobert, "Etude d'un systèmehybrideéolienphotovoltaïque avec stockage. Dimensionnement et analyse du cycle de vie", Eur. J. Electr. Eng, 15, 6, pp. 659-678, (2012).

9. R. Messenger, J. Ventre, "Photovoltaic Systems Engineering", Third Edition. Boca Raton: Taylor \& Francis Group, LLC, (2010).

10. L. Elmahni, L. Bouhouch, A. Moudden, "Smart management of a photovoltaic pumping station Located in the Agadir region", Int. J. Innov. Appl. Stud., 18, 4, pp. 1216-1227, (2016).

11. S. Farhat, M. R. El MoutawakilAlaoui, A. Kahaji, L. Bouhouch, "MPPT Efficiency Test by Neural Networks and P\&O Algorithm", Int. Rev. Electr. Eng., 8, 5, pp. 1548-1555, (2013).

12. MATHWORKS, "User's Guide", 2013A, (2013).

13. KIMO Instruments, Solarimètre SL 200, http://www.kimo.fr/fr/portable/sl-200, Consultedat 06/04/2018.

14. B. Chabot, "From Costs to Prices: Economic Analysis of Photovoltaic Energy and Services", Prog. Photovo Res. Appl, 6, pp. 55-68, (1998). 